\title{
"I Can't Move"
}

\author{
Victor J. Vorhees
}

Mrs. L, a 78-year-old widow with a large, very verbal, gregarious family, was recently a patient of mine in the emergency department. She had two minimally fractured ribs from a fall in her home. Four days later, she fell again, in her bathroom. In accordance with her history, she was unable to get to her feet, but scooted out of the bathroom onto her bedroom carpet.

After lying there for an unknown time, "maybe half an hour," feeling very "weird," she managed to get herself back into her bed. She called a son, who rushed over, checked on her, found her to be OK and left. A daughter brought her to the office later that day to be seen by me.

Despite efforts to get her to describe how she felt, she could describe her feeling(s) only as "weird!" As she continued to talk about this and other incidents, it became intuitively clear to me she was afraid that her children would ignore her and at the same time that they would control her life. She and the daughter with her talked about Mrs. L. wanting the daughter to move in with her and, conversely, the daughter wanting Mrs. L. to move into her house. Mrs. L. was refusing to leave her own home.

I finally suggested she was saying, like a teenager, "help me, but don't you tell me what to do!" Her daughter was nodding, and Mrs. L. admitted it fit.

I suggested we could approach this based on exploration of her feelings and fears, or we could go from test to test looking for an answer. She did not want to do the tests. She talked about not wanting to be alone, about needing to be with people, for they "pump" her up. She talked of losing friends, and about other losses. She also wanted me to feel a lump on her hip, which she said was from her fall. It was a normal trochanter. She felt it had "gone

Submitted 18 March 2003.

From Family Health Care, PA, Fredonia, Kansas. Address correspondence to: Victor J. Vorhees, MD, Family Health Care PA, 712 Madison, PO Box 516, Fredonia, KS 66736 (e-mail: familyhealthcarepa@twinmounds.com). down" a lot since her fall. Neurological examination showed no abnormality. Laboratory studies showed normal hemoglobin, and satisfactory hemoglobin A1C (she has well-controlled diabetes).

One week later, she returned to the office and reported having wakened the previous day with her left leg moving uncontrollably. She demonstrated by moving it about, smoothly, with random movements, nothing like a seizure. Her other leg, and both arms and the rest of her body were all "numb." She could neither feel nor move any part of it. After what seemed like a long time to her, it all stopped, and she got out of bed. She seemed to have been frightened by the experience.

I explained at length that this did not fit any disease and did not have an anatomic pattern for neurological problems. A son was with her at this visit. He understood what I was saying and assented when I told her I felt this might be a result of anxiety about giving up her independence. She listened, but could not see that she was making demands on others without regard to what she could do to make it easier for them to care for her. In a previous conversation she had called herself "a control freak."

We reviewed the reports of two CT scans of the brain done over a 4-year period (before my involvement in her care), which showed mild cerebral atrophy, and nothing else.

On the phone, before this visit, she had told me that her family wanted her to see another doctor. I took that to mean transfer of care, but she meant consultation. It was her understanding that the family wanted another physician involved because I was not finding the cause of her problems.

She wanted a nearby physician, and I suggested that I would send her to a neurologist about 60 miles away (nearby for us). She wanted to talk with her family about this and then make her own appointment. My diagnosis at this point was abnormal involuntary movements, probably psychophysiologic, in a person living alone, in an anxiety state caused by aging and loss of independence. 
One week later, Mrs. L. called to say she had experienced another episode on awakening in which she had been unable to move her head, either arm, her upper body, or one leg but could move the other leg quite well. She did not try to get up, but after about 90 minutes was able to get up and go to the bathroom. She felt it was no use to call 911 because her door was locked. She had not arranged for, but still wanted, a consultation. I arranged an appointment with the neurologist for 5 days later.

One day before her appointment with the neurologist, she returned having had "the worst one ever." On awakening, she could control movements of only her head, nothing else, and her entire body, except for her head, was shaking and trembling uncontrollably. After some time, she was able to reach up to a wall phone and call one of her children who has a key to her house. When the daughter arrived she found Mrs. L. sitting on the couch, apparently normal. The daughter, the third of her children to accompany her, was with her at this visit.

I decided to risk an effort at interpretation. I asked what her problem had been in each of these episodes. She said, “Well, I can't. . . I can't. . . well, I can't. . " But she could go no further. With some prompting, she finally was able to say, "I can't move!" I suggested that "to move" can have several meanings.
Her daughter was sitting to one side and slightly behind the patient. She saw immediately what I was suggesting, and was smiling and nodding her head. I pointed out that for three visits she had talked not only of inability to move various body parts but also inability to bring herself to move in with her daughter.

Ten days later, having seen the neurologist (from whom I had not yet received any report), she returned. She needed an EKG before having (previously scheduled) cataract surgery. She was very upbeat, pleasant, and relaxed (and, as always, talkative). She told me the neurologist had told her "the very same things" I had told her- "it's nerves." He prescribed Paxil, which she was taking, and Ativan to have on hand to take if she had any more spells. He also scheduled nerve conduction studies and an EEG. She praised my care, my wisdom in sending her to the neurologist, and emphasized repeatedly that he said my diagnosis was correct.

She left the room, and I went on to another patient. But, after checking out, she returned to the reception desk and told the receptionist to tell me she had moved in with her daughter and had had no more spells of any kind-nor has she had any since. The symbolism involved continues to seem striking to me-_I can't move!" 